
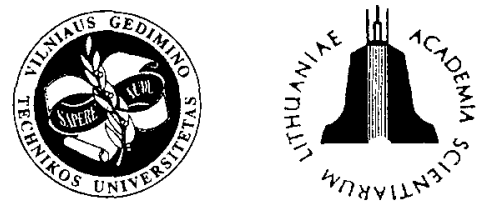

ISSN 1392-3730

JOURNAL OF CIVIL ENGINEERING AND MANAGEMENT

http:/www.vu.lt/english/edition

2002, Vol VIII, No 2, 7782

\title{
PUNCHING SHEAR BEHAVIOUR ANALYSIS OF RC FLAT FLOOR SLAB-TO-COLUMN CONNECTION
}

\author{
Povilas Vainiūnas', Vladimiras Popovas ${ }^{2}$ and Andrei Jarmolajev ${ }^{3}$ \\ 1, 2 Dept of Reinforced Concrete and Masonry Structures, Vilnius Gediminas Technical University, \\ Sauletekio al. 11, LT-2040 Vilnius, Lithuania. E-mail: gelz@st.vtu.lt \\ ${ }^{3}$ Dept of Architectural Engineering, Vilnius Gediminas Technical University, \\ Sauletekio al. 11, LT-2040 Vilnius, Lithuania
}

Received 01 Jun 2001; accepted 05 Febr 2002

\begin{abstract}
The paper presents information about theoretical investigations and based on computer modelling and analysis research methods of flat floor slab-to-column joint behaviour for punching obtained by authors. Main principles of calculation and design methods of flat slab-to-column support under punching according to variety of international design coded are observed and compared. The design problems of beamless floor systems for shear with bending are discussed. The set of variables, such as lateral flexural reinforcement, bending moment to shear force ratio, span-to-slab depth ratio and slab thickness to column depth ratio, which may have an influence on flat two-ways floor slab punching shear strength is established and computer modelling analysis methods are applied to investigate the problem.
\end{abstract}

Keywords: punching shear strength, flat floor slab-to-column connection, shear crack inclination angle, lateral flexural reinforcement, shear force to bending moment ratio, numerical analyses and computer modelling methods

\section{Introduction}

In design of beamless flat floor slab-to-column connection its limit state is commonly expressed by punching shear strength, since it is obviously lower than slab shear strength. Commonly the main design aim of reinforced concrete slabs near the support zone is to avoid brittle and rapid punching failure mode.

Comparing different punching shear strength analytical calculation methods one may find that most national design codes deal only with evaluation of concrete strength basically expressed by tensile strength and shear reinforcement within the same specific area around the column support, the so-called punching pyramid. But there are more significant factors that may have an influence on punching resistance. There exists among them an amount of flexural longitudinal reinforcement distributed within the support zone, bending moment and shear force transfer between slab and column, span to slab depth ratio, slab thickness and column depth ratio, etc.

The main difference in results between various design methods appears due to different calculation approach of punching pyramid basis perimeter. The punching area calculation according to EC2 [1], BS8110 assumes that punching crack is inclined about $33,7^{\circ}$ to slab plane, while DIN [2], SNiP [3] assume this angle to be equal to $45^{\circ}$, with the same situation in Australian AS3600 and American ACI318 [4] design codes.
Some design codes evaluate the influence of axial forces (AS3600, ACI318) and bending moments (ACI318, BS8110 and SABS 0100) acting in slab within the support area to the punching shear strength. Also EC2 recommends to take into account the intensity of slab longitudinal flexural reinforcement crossing slab-to-column connection zone. However, there is no common rule set for this recommendation.

During the last ten years a number of experimental and numerical investigations was applied in order to improve design codes recommendations for punching shear calculation in terms of evaluation of some essential factors, which have an influence on punching shear behaviour and affect failure mode.

The most important of them are: shear reinforcement type and shape from various studs and stirrups [58], to special shear heads and hat-shaped units [9, 10], bending moment and shear forces transfer from slab to column [11-13], as well as relationship between flexural and punching failure modes [14], tensile strength of concrete, amount and percentage of lateral flexural reinforcement crossing slab to column connection, slab thickness and radius of punching crack initiation $[15,16]$, slabcolumn rigidity and span-to-slab depth ratios [17].

This investigation is the next step of research applied by authors in order to figure out the effect of various factors on slab-column connection behaviour under punching [18]. 


\section{Design of punching shear}

\subsection{ACI318}

Section 11.12 of $\mathrm{AC} 1318$ defines requirements for punching shear [4]. The critical perimeter is defined to occur at $d / 2$ from the column face (Fig 1), where $d$ is the depth to the centroid of the tension reinforcement, but $d$ shall not be taken as $<0.8 \mathrm{D}$.
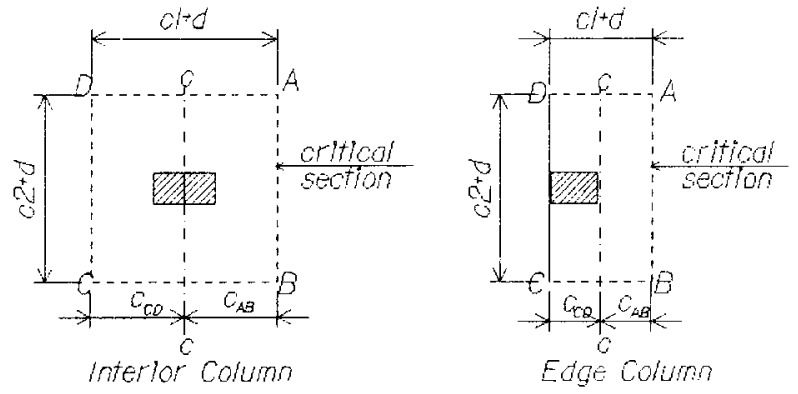

Fig 1. Critical punching area according to $\mathrm{ACI} 318$

The nominal shear strength provided by concrete for non prestressed slabs $V_{c}$. is taken as the smallest of:

$$
V_{c}=\left(\frac{1}{6}+\frac{1}{3 \beta_{c}}\right) \sqrt{f_{c}^{\prime} b_{0} d}
$$

where $\beta_{c}$ is the ratio of the long side to short side of the column;

$$
V_{c}=\left(\begin{array}{c}
\alpha_{s} d \\
12 b_{0}+\frac{1}{6}
\end{array}\right) \sqrt{f_{c}^{\prime} b_{0} d}
$$

where $\alpha_{c}$ is 40 for interior columns (30 for edge columns and 20 for corner columns);

$$
V_{c}=\frac{\sqrt{f_{c}^{\prime} b_{0} d}}{3}
$$

\subsection{EC 2}

Section 4.3 .4 of EC2 defines the punching shear requirements for slabs [1]. The critical perimeter is defined at a point $1.5 \mathrm{~d}$ from the loaded area (Fig 2), where is effective depth of the slab (depth to the centroid of the tension reinforcement), but not less as $0.8 \mathrm{D}$.

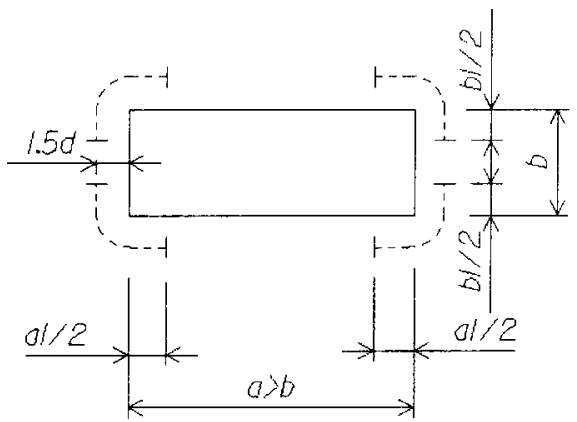

Fig 2. Critical punching perimeter according to EC2
The shear resistance of non-prestressed slabs are calculated as follows:

$$
V_{R d 1}=\tau_{R_{d}} k\left(1.2+40 p_{1}\right) d,
$$

where concrete shear strength $\tau_{R d}$ varies according to the concrete strength $f_{c k} ; p_{1}$ relates to tension steel in the $x$ and $y$ directions respectively, $p_{k}$ and $p_{1 y}$, $\left(p_{1} \leq 0.015\right) ; k=(1.6-d)>1.0 ; d$ is effective depth of the slab (ie depth is the centroid of the tension reinforcement but $d$ shall not be taken as $<0.8 D$ ).

\subsection{DIN 1045}

Section 22.5.1.1. of DIN 1045 defines the requirements for punching shear [2]. The critical perimeter is defined to occur at $\mathrm{d} / 2$ from the column face.

The shear resistance of non-prestressed slabs are calculated as follows:

$$
Q_{R}=\tau_{R} u h_{m}
$$

where $\tau_{R}$ is concrete shear strength; $u$ is the critical perimeter; $h_{m}=d$ is effective depth of the slab.

\subsection{SNiP 2.03.01-84}

Section 3.42. of SNiP 2.03.01-84 defines the requirements for calculation of punching shear [3]. The critical perimeter $u_{m}$ is defined as average perimeter of both top and bottom surfaces of punching pyramid.

The shear resistance of slabs are calculated as follows:

$$
F=\alpha R_{b l} u_{m} h_{o}
$$

$\alpha$ is coefficient of concrete type ( $d=1$ for normal weight concrete); $R_{b t}$ is concrete tension strength; $h_{o}$ is effective depth of the slab (the same as $d$ above).

As it is shown above, only Eurocode defines special design conditions for longitudinal flexural reinforcement of concrete slab inside the punching area.

\section{Analysis models of flat floor plate-column joints}

Influence of some factors on beamless flat slab punching shear resistance is hardly evaluated by analytical methods. At the same time the laboratory testing conditions are too simplified to simulate the natural structure behaviour and stress-strain state details. The application of modern computer modelling simulation technologies, based on finite elements analysis methods open wide possibilities for accurate and detail numerical investigation of structural behaviour $[15,19]$.

Numerical analysis of beamless flat slab-to-column joint was carried out, in order to evaluate all mentioned above factors, which may have any kind of significance for the behaviour of such type of structural parts.

For the calculations, the 2.5D model comprising twospan frame and floor slab stripe with two-floor height columns was taken (see Fig 3). 


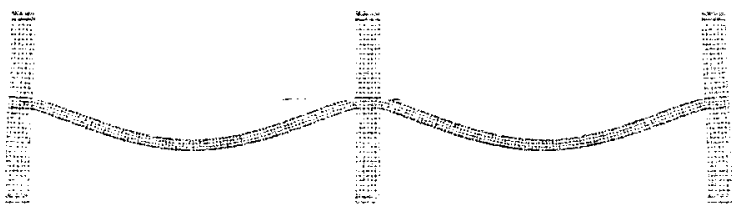

Fig 3. Analysis model

The cross-section of the column was $400 \times 400 \mathrm{~mm}$, while the slab depth was $200 \mathrm{~mm}$. The effect of slabcolumn rigidity ratios was analysed using different crosssectional dimensions: the column cross-section was $300 \times 300 \mathrm{~mm}$ with slab depth $150 \mathrm{~mm}$ in first case, and $500 \times 500 \mathrm{~mm}$ column section with $250 \mathrm{~mm}$ slab depth in the second case.

The width of effective (column) slab strip was 800 and $1000 \mathrm{~mm}$ respectively for $45^{\circ}$ and $33^{\circ}$ angle of inclination of punching planes. The results were compared with minimal $400 \mathrm{~mm}$ (flat frame) and maximum recommended $1500 \mathrm{~mm}$ (quarter of span) depth of slab strip. The considered spans were most commonly used -6.0 ; $4.5 ; 7.5$ m length.

The behaviour of non-reinforced concrete slab-tocolumn connection model prior to failure was analysed in comparison with identical reinforced concrete models, when:

1. the slab was reinforced only by longitudinal tension reinforcement, which intensity varied depending on bar diameter - $\emptyset 10 \mathrm{~mm}(\mu \%=0.40) ; \varnothing 12 \mathrm{~mm}(\mu \%=$ $0.50) ; \varnothing 16 \mathrm{~mm}(\mu \%=1.0) ; \emptyset 20 \mathrm{~mm}(\mu \%=1.57)$; $\varnothing 22 \mathrm{~mm}(\mu \%=1.90) ; \varnothing 25 \mathrm{~mm}(\mu \%=2.45)$;

2. the slab was reinforced by longitudinal bars and shear ones of different quantity and distribution patterns in the connection to column zone;

3. the slab was reinforced by longitudinal bars and some amount of bent reinforcement of different quantity and distribution patterns in the punching zone.

In all cases, the amount of longitudinal flexural reinforcement in span was sufficient to provide strength and proof from failure in the normal section.

The concrete grade used in modelling was B25, reinforcement grade - A-III. Determining the control joint strength parameters, all the concrete and reinforcement strength characteristics were taken as their characteristic values.

Structural models were loaded in both spans by uniformly distributed load until the failure of the joint due to punching shear. In order to reach the result as close as possible to the real material behaviour, the nonlinear concrete approach was used. Numerical modelling was performed using finite element analysis software package COSMOS/M [20].

\section{Non-linear concrete model}

The concrete model was a three-dimensional, rateindependent model with a bounding surface [21, 22]. The model adopts a scalar representation of the damage re- lated to the strain and stress states of the material. The bounding surface in the stress space shrinks uniformly as the damage due to strain softening and/or tension cracks accumulates. The material parameters depend on the damage level, the hydrostatic pressure, and the distance between the current stress point and the bounding surface (Fig 4).

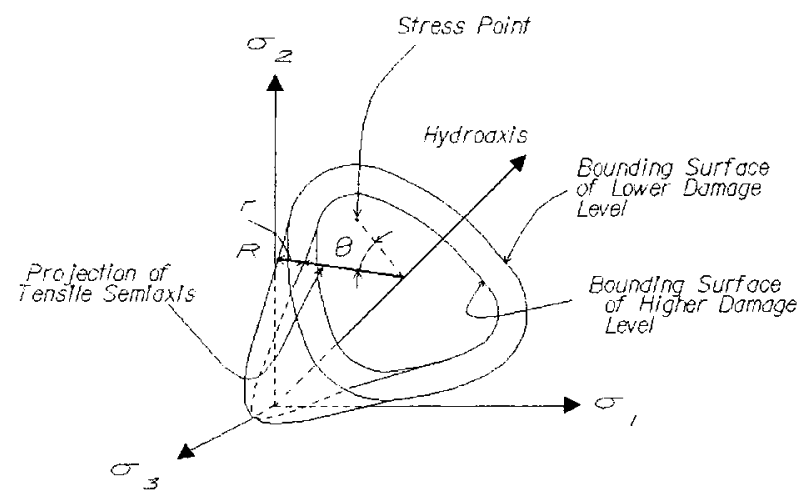

Fig 4. Bounding surface

The bounding surface function is:

$f\left(\sigma_{i j}, k_{\max }\right)=\frac{0.25 j_{2}+3.1 \sqrt{j_{2}}}{4 I_{1}+3.492}(\cos (3 \theta)+5)-H\left(k_{\max }\right)$

where $H\left(k_{\max }\right)=\frac{40}{39+k_{\max }^{2}}$;

$\sigma_{i j}$ is the normalised stress tensor (in respect of the ultimate compression strength $f_{c}^{\prime}$ ), $I_{1}$ and $j_{2}$ are the first stress and the second deviatoric normalised stress invariants respectively, $\theta$ is the loading angle, and $k_{\max }$ is the maximum damage coefficient.

The damage coefficient represents the damage due to strain hardening or softening. The damage coefficient value is always positive and its magnitude in conjunction with the hydrostatic pressure represents the damage due to compression and tension cracking. For instance, the damage in a uniaxial compression test at the ultimate strength is normalised to be 1.0 and its value is approximately 0.20 for uniaxial tension test. The damage is obtained by integrating the incremental damage coefficient that depends on the plastic strain and the distance from the current stress state and the bounding surface.

$$
\begin{gathered}
d k=\frac{R d D}{H^{P} F_{1}\left(I_{1}, \theta\right)} \quad \text { for deviatoric loading; } \\
d k=\begin{array}{c}
d \gamma_{0}^{p} \\
F_{1}\left(I_{1}, \theta\right)
\end{array} \text { for post-failure; }
\end{gathered}
$$

where $H^{P}=$ plastic shear modulus; $F_{1}\left(I_{1}, \theta\right)$ is a function of $I_{1}$ and $\theta$ and loading conditions; $D$ is normalised distance $r / R ; r$ is distance from the projection of the current stress point on the deviatoric plane to the 
hydroaxis; $R$ is distance of the bounding surface from the hydroaxis along the deviatoric stress direction.

The model is defined by two material parameters, which are:

$F P C$ - the concrete ultimate strength $\left(f_{c}^{\prime}\right)$;

$E P S U$ - the ultimate strain $\mathrm{e}_{0}$ (the strain at stress of $f_{c}^{\prime}$ in the uniaxial compression test).

The low strain elasticity modulus $(E)$, bulk modulus $\left(K_{t}\right)$, and shear modulus $\left(H^{P}\right)$ are set to:

$$
\begin{aligned}
& E=57,000 \frac{\varepsilon_{0}}{\sqrt{f_{C}^{\prime}}} ; \\
& H_{p}=\begin{array}{c}
H^{*} C_{l} \\
F_{1}\left(I_{1}, \theta\right)
\end{array} ;
\end{aligned}
$$

where

$$
\begin{aligned}
& H^{*}=\begin{array}{l}
2.4 R(1-D)^{0.65 D^{2}} \\
\left(1+0.7 K_{\max }^{2}\right) A_{L}
\end{array} \text { - for deviatoric loading; } \\
& H^{*}=\frac{2.4 R}{\left(1+0.7 K_{\max }^{2}\right) A_{L}} \text { - for deviatoric unloading; } \\
& C_{t}=1.0-\text { for } D<0.9 ; C_{t}=1.0 E 5(1-D)^{5} \text { - for } \\
& 0_{0.9} ; \\
& A_{L}=\text { a factor that depends on damage parameter. }
\end{aligned}
$$
$D<0.9$;

The parameters are temperature independent. Moreover, the model should be used in conjunction with small strain formulation.

Under tension stresses, the model behaves as a nonlinear strain-hardening material until it reaches the tension strength and starts to behave as a perfectly plastic material. The maximum tensile strength for uniaxial test is considered as:

$$
f_{l} \approx 0.17 f_{c}^{\prime} .
$$

\section{Analysis results}

During the analysing of slab-to-column joint working conditions, the main emphasis was concentrated to clear out the mechanism of the punched-out pyramid surface formation and the failure process propagation. This process was observed for different ratios of bending moment and shear force, which was achieved by changing the slab span and the slab-column rigidity ratios.

The analysis results of non-reinforced slab at the slab-to-column joint are represented by graphs on Fig 5 . The graphs show the principal stresses variation dynamics through the slab depth $(\mathrm{h})$ in the slab to column contact and in the hypothetical punched-out pyramid base, defined at the level of axis of the upper longitudinal reinforcement.

At the early loading stages, the clear balance of tensile and compressive stresses in the slab-column contact zone is observed. The distribution topology for normal and principal stresses is almost identical. The increase of loading causes the lengthening and insignificant deep- ening of the principal stress zone. Neutral axis is shifted to about $0.35 \mathrm{~h}$ level and remains quite stable until 4 th loading stage (50-60\% of failure loading), after which the process of progressive collapse takes place. At this stage, the formation of punched-out pyramid base is over; increase of the loading causes only the pyramid height increases. Principal stress zone progressively increases in its depth; neutral axis constantly shifis down and is at (0.15-0.2) $h$ level at the moment of failure. The depth of the compressive zone is about $30 \mathrm{~mm}$ at the failure moment.
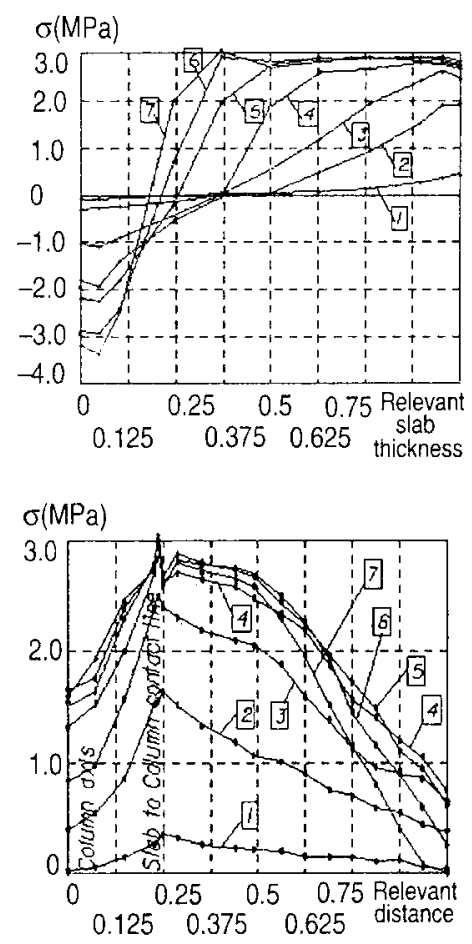

Fig 5. The principal stress dynamics change throughout the depth of non-reinforced slab at the slab-to-column joint (a) and hypothetical punched-out pyramid base level (b): $1-3,7 \% ; 2-18,5 \% ; 3-33,3 \% ; 4-55,5 \% ; 5-70 \%$; $6-85 \% ; 7-100 \%$ - loading stages

First vertical cracks appear at the slab-column joint topmost corner at the $33 \%$ of the failure loading. While the loading increases to $40-50 \%$ of failure value, providing further principal stress zone length increase, the origin of collapse appears at the distance $1 / 2 \mathrm{~h}$ from the corner. The cracks formed at this zone are inclined at $45^{\circ}-60^{\circ}$ in respect of the slab plane. Collapse zone rapidly develops, increases in width and depth and propagates towards the lowermost angle of the support. At about $70 \%$ of failure loading, an identical kernel of maximum principal stresses appears at the slab midpoint, being separated from the original failure zone. This is how the punch-out pyramid is formed. At the failure stage, the very thin compression zone is shear-cut.

At the failure stage, the angle of inclination of the side planes of the punched-out pyramid lies within $40^{\circ}-55^{\circ}$ sector (Fig 6). From the graph shown in Fig 5 b, 

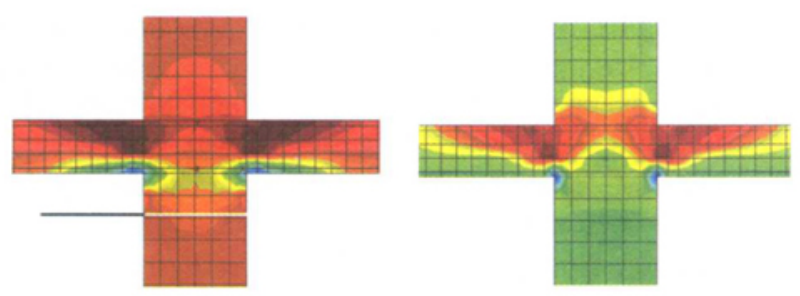

Fig 6. Normal $\sigma_{x}$ (Sigma $X$ ) and principal $\sigma_{1}$ (Principal_ $I$ ) stress distribution topology in the slab-column joint at the failure stage

one may see that the edge of the base of punched-out pyramid is at the distance $h$, ie, equal to slab depth, from the column side surface; this means that the inclination angle of pyramid side planes is $45^{\circ}$. Having $6 \mathrm{~m}$ span, the mean value of this angle tends to increase from $40^{\circ}$ for $160 \mathrm{~mm}$ slab depth up to $45^{\circ}-47^{\circ}$ for $200 \mathrm{~mm}$ slab depth, and even $55^{\circ}$ for depth $h=250 \mathrm{~mm}$. Changing the span from $4,5 \mathrm{~m}$ to 6,0 or $7,5 \mathrm{~m}$, the ratio of bending moment and shear force at the joint also changes, varying from $\mathrm{M} / \mathrm{Q}=0,77$ to 1,03 and 1,28 , respectively. Some greater mean values of this angle $\left(52^{\circ}\right)$ observed in cases of small spans, and similar results $\left(45^{\circ}-50^{\circ}\right)$ were obtained for 6,0 and $7,5 \mathrm{~m}$ slab spans.

Analysing the behaviour of the slabs with longitudinal reinforcement at the slab-to-column joint, influence of the flexural reinforcement intensity on the punching shear resistance of the slab was also considered. The punching shear resistance values for all the considered analysis cases are presented in Table 1 .

Table 1. Punching force Fsh values at the slab-column joint for the cases of non-reinforced and longitudinally reinforced slabs

\begin{tabular}{|c|c|c|cc|c|}
\hline \multirow{2}{*}{$M / Q$} & \multicolumn{5}{|c|}{$F_{s h} / U_{m}{ }^{*} h_{0}\left(\mathrm{MN} / \mathrm{m}^{2}\right)$, when reinforcement ratio } \\
in $\%$ is \\
\cline { 2 - 6 } & 0,44 & 0,50 & 1,00 & 1,90 & 2,45 \\
\hline 0,77 & 0,764 & 0,788 & 0,883 & 1,009 & 1,023 \\
\hline 1,03 & 0,590 & 0,627 & 0,724 & 0,814 & 0,823 \\
\hline 1,28 & 0,441 & 0,472 & 0,553 & 0,635 & 0,642 \\
\hline
\end{tabular}

Analysis results shown in Fig 7 depict the principal stress change dynamics throughout the slab depth $h$ at the contact zone with column and at the base of the punched-out pyramid, measured at the upper longitudinal reinforcement level from the column axis.

Even at the early loading stages, the influence of longitudinal reinforcement to the distribution of normal and principal stresses may be seen. Loading increase above $50 \%$ of its ultimate value causes more significant elongation of principal stress zone than in the case of non-reinforced slab. Thus, the neutral axis shifts down just to $(0,35-0,375) h$ depth level and remains at it until structure failure. The depth of the compressive zone in this case is about $60 \mathrm{~mm}$, ie twice bigger than for nonreinforced slab. The boundaries of punched-out pyramid are not so clearly defined, but the tensile and compressive slab layers are well expressed. All this leads to conclusion that longitudinal reinforcement indeed influences the stress-strain state of the joint.

At the failure stage the angle of punching surface is not well defined in case of slab with longitudinal reinforcement. Failure zone lies within $30^{\circ}-52^{\circ}$ sector range (Fig 8). From the graph (Fig 7b), one may find that the edge of the punch-out pyramid base is at about $300 \mathrm{~mm}$ distance from the column side surface. So, in that case the inclination angle of punch-out pyramid side surfaces equals $33^{\circ}$.

Numerical simulation shows that the longitudinal flexural reinforcement increases the punching resistance of the slab. Graph, depicted in Fig 9 shows that the amount of longitudinal reinforcement influences the punching resistance of $200 \mathrm{~mm}$ thickness slab in quite wide range of reinforcement ratio $\mathrm{m} \%=0,40-2,5 \%$ depending on the balance between bending moment and shear force (M/Q ratio). However, the limit of longitudinal reinforcement amount effect may be set at about $2 \%$, resulting in similarity to Eurocode recommendations $(1,5 \%)$.
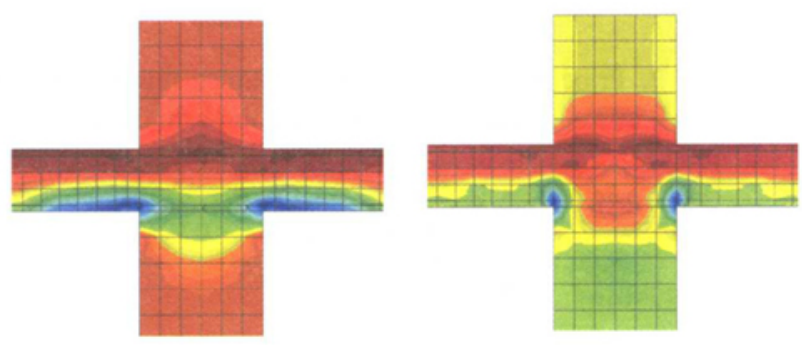

Fig 8. Normal $\Sigma_{Y}$ (Sigma $X$ ) and principal $\sigma_{1}$ (Principal_I) stress distribution topology in the slab reinforced by longitudinal bars in the slab-column joint at the failure stage

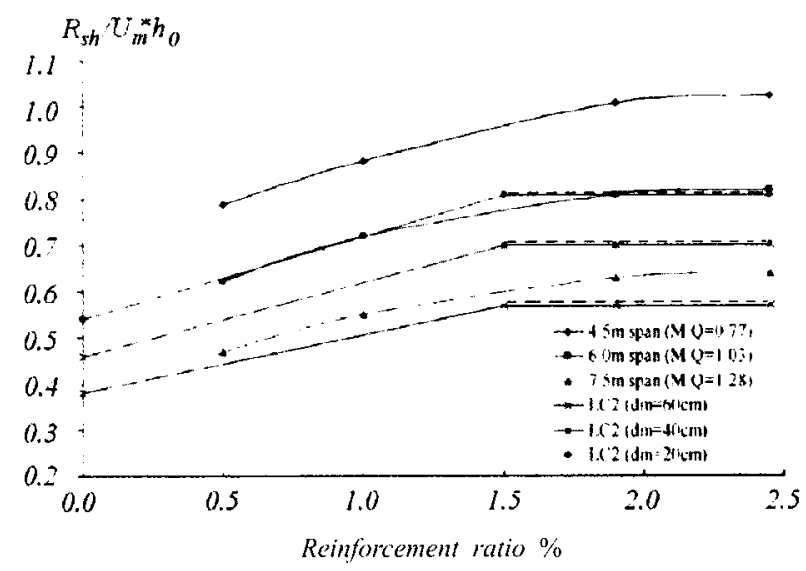

Fig 9. The influence of reinforcement intensity to punch resistance obtained in experiment for slab of $h=200 \mathrm{~mm}$, compared to theoretical values calculated according EC2 

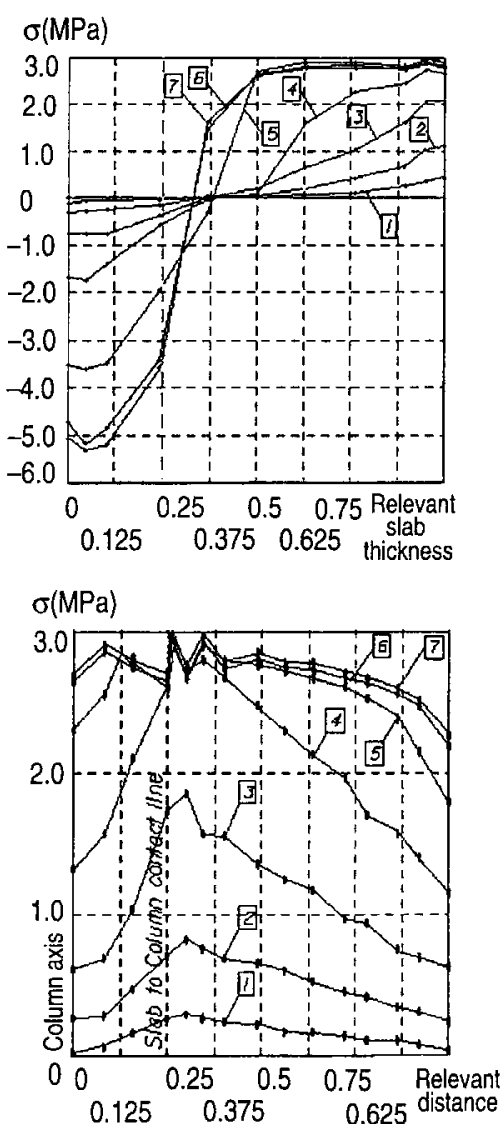

Fig 7. Principal stress change dynamics throughout the depth of longitudinally reinforced slab at the slab-column joint (a) and hypothetical punched-out pyramid base level (b): $1-3,7 \% ; 2-18,5 \% ; 3-33,3 \% ; 4-55,5 \% ; 5-70 \%$; $6-85 \% ; 7-100 \%$ - loading stages

\section{Conclusions}

1. Numerical experiments show that non-reinforced and longitudinally reinforced slab punched-out concrete pyramid plane inclination angle vary around $45^{\circ}$ for nonreinforced slabs and is near to $33^{\circ}$ for reinforced slabs.

2. Magnitude of the punching force depends on amount of longitudinal flexural reinforcement in punching shear area. With an increase of amount of longitudinal reinforcement, the punching force also increases.

3. Value of punching force depends on the ratio of shear forces and bending moments acting within critical section; the more is the ratio, the greater punch resistance may be achieved.

4. The maximum stresses $\sigma_{x}, \sigma_{p r 1}, \sigma_{p r 2}$ in the limit state within punched section reach the same values, independently of the ratio of shear forces and bending moments.

\section{References}

1. Eurocode 2: Design of concrete structures - Part 1: General rules and rules for buildings, 1992. 222 p.

2. DIN 1045 Concrete and Reinforced Concrete Design Code (Baunormen Beton- und Stahlbetonbau DIN 1045), BeuthVertrieb GmbH, 1972. 351 p. (in German).
3. SNiP 2.03.01-84 Concrete and Reinforced Concrete Structures. Design Codes (Бетонные и железобетонные конструкции. Нормы проектирования). Moscow: CTIP Gosstroja SSSR, 1985. 77 p. (in Russian).

4. Fintel M., editor. Handbook of Concrete Engineering, 2nd ed., Van Nostrand Reinhold, New-York, 1985. 801 p.

5. Marzouk H., Jiang D. Experimental Investigation on Shear Enhancement Types for High-Strength Concrete Plates. $A C l$ Structural Journal, 1997. Vol 94, No 1, p. 49-58.

6. Starosolski W., Pajak Z., Mazanowska J. Structural solution of cast-in-situ floor slab-to-column joint supporting zone. Engineering and Building Construction (Inzynieria i Budownictwo), 1978, No 7, p. 19-22 (in Polish).

7. Oliveira D. R., Melo G. S., Regan P. E. Punching Strengths of Flat Plates with Vertical or Inclined Stirrups. ACI Structural Journal, 2000, Vol 97, No 3, p. 485-494.

8. Elgabry A. A., Ghali A. Design of stud-shear reinforcement for slabs. ACI Structural Journal, 1990, Vol 87, No 3 , p. 393-404.

9. Yamada T., Nanni A., Endo K. Punching Shear resistance of flat slabs: Influence of reinforcement type and ratio. ACI Structural Journal, 1992, Vol 89, No 5, p. 555-563.

10. Report by ACI Committee. Abstract of: Shear Reinforcement for slab. ACI Structural Journal, 1992, Vol 896, No 5, p. 587-589.

11. Elgabry A. A., Ghali A. Moment transfer by shear in slabcolumn connections. ACI Structural Journal, 1996, Vol 93, No 2, p. 249-257.

12. Elgabry A. A., Ghali A. Transfer of Moments between Columns and Slabs: Proposed Code Revisions. ACI Structural Journal, 1996, Vol 93, No 1, p. 93-106.

13. Elgabry A. A., Ghali A. Design for Punching Shear Strength with ACI 3/8-95. ACI Structural Journal, 1999, Vol 96, No 4, p. 807-816.

14. Menetrey $\mathrm{Ph}$. Relationship between Flexural and Punching Failure. ACI Structural Journal, 1998, Vol 95, No 4, p. 412-419.

15. Menetrey Ph. Analytical Computation of the Punching Strength of Reinforced Concrete. ACI Structural Journal, 1996, Vol 93, No 5, p. 482-498.

16. Alexander S. D. B., Simmonds S. H. Tests column-flat plate connections. ACI Structural Journal, 1992, Vol 893, No 5 , p. $495-502$.

17. Lovrovich J. S., Mclean D. I. Punching Shear behavior of Slabs with varying span-depth ratios. ACI Structural Journal, 1990, Vol 87, No 5, p. 521-534.

18. Vainiūnas P., Popovas V., Jarmolajev A. Strees-strain Analysis of Cast-in-situ Floor Slab in Supporting Collar Zone. In: Proceedings of 6th intern conference "Modern Building Materials, Structures and Techniques", May 1921, 1999, p. 139-144 (in Lithuanian).

19. Polak M. A. Modelling Punching Shear of Reinforced Concrete Slabs Using Layered Finite Elements. ACI Structural Journal, 1998, Vol 95, No 1, p. 71-80.

20. COSMOS/M 2.0 Basic FEA System, Structural Research and Analysis Corp., 1997. $612 \mathrm{p}$.

21. Moussa R. A. and Buykozturk O. Bounding Surface Model for Concrete. Nuclear Engineering and Design, 1990, Vol 121, p. 113-125.

22. Chen E. S. and Buykozturk O. Damage Model for Concrete in Multi-axial Cyclic Stress. J. Engineering Mechanics, ASCE, 1985, p. 111 (6), p. 111-116. 